\title{
Cluster observations of a complex high-altitude cusp passage during highly variable IMF
}

\author{
M. G. G. T. Taylor ${ }^{1,2}$, M. W. Dunlop ${ }^{3}$, B. Lavraud ${ }^{1,4}$, A. Vontrat-Reberac ${ }^{5}$, C. J. Owen ${ }^{2}$, P. Décréau ${ }^{6}$, P. Trávníček ${ }^{7}$, \\ R. C. Elphic ${ }^{1}$, R. H. W. Friedel ${ }^{1}$, J. P. Dewhurst ${ }^{2}$, Y. Wang ${ }^{1}$, A. Fazakerley ${ }^{2}$, A. Balogh ${ }^{8}$, H. Rème ${ }^{4}$, and P. W. Daly ${ }^{9}$ \\ ${ }^{1}$ Space and Atmospheric Sciences, Los Alamos National Laboratory, New Mexico, USA \\ ${ }^{2}$ Mullard Space Science Laboratory, University College London, UK \\ ${ }^{3}$ Rutherford Appleton Laboratory, Didcot, Oxfordshire, UK \\ ${ }^{4}$ Centre d'Etude Spatiale des Rayonnements, Toulouse, France \\ ${ }^{5}$ Centre d'étude des Environnements Terrestre et Planétaires, Velizy, France \\ ${ }^{6}$ LPCE/CNRS 45071 Orleans Cedex 2, France \\ ${ }^{7}$ Institute of Atmospheric Physics, The Academy of Sciences of the Czech Republic \\ ${ }^{8}$ Imperial College of Science Technology and Medicine, London, UK \\ ${ }^{9}$ Max-Planck-Institut für Aeronomie, D-37191 Katlenburg-Lindau, Germany
}

Received: 2 February 2004 - Revised: 29 June 2004 - Accepted: 16 August 2004 - Published: 3 November 2004

\begin{abstract}
On 26 February 2001, the Cluster spacecraft were outbound over the Northern Hemisphere, at approximately 12:00 MLT, approaching the magnetosheath through the high-altitude (and exterior) cusp region. Due to macroscopic motions of the cusp, the spacecraft made multiple entries into the exterior cusp region before exiting into the magnetosheath, presenting an excellent opportunity to utilize the four spacecraft techniques available to the Cluster mission. We present and compare 2 methods of 4-spacecraft boundary analysis, one using PEACE data and one using FGM data. The comparison shows reasonable agreement between the techniques, as well as the expected "single spacecraft" plasma and magnetic signatures when associated with propagated IMF conditions. However, during periods of highly radial IMF (predominantly negative $B_{X}$ GSM), the 4-spacecraft boundary analysis reveals a dynamic and deformed cusp morphology.
\end{abstract}

Key words. Magnetospheric physics (Magnetopause, cusp and boundary layers; solar wind-magnetosphere interactions; Magnetospheric configuration and dynamics)

\section{Introduction}

The Earth's magnetospheric cusps represent topological boundaries, separating the dayside field lines from those extending into the lobes, along the magnetotail. Originally proposed by Chapman and Ferraro (1931), these magnetic null points were observed as bands of magnetosheath like plasma and determined to be permanent features of the polar magne-

Correspondence to: M. G. G. T. Taylor

(mggt@mssl.ucl.ac.uk) tosphere, and designated "polar cusps" (Heikkila and Winningham, 1971; Frank, 1971). Such observations suggested that cusps were fundamentally important in the process of plasma transfer from the magnetosheath into the magnetosphere (Paschmann et al., 1976; Hulqvist et al., 1999) and favorable to observe the signatures of magnetic reconnection between the interplanetary magnetic field and the magnetosphere (Dungey, 1961). At altitudes of $\sim 8-10 R_{E}$, the high-altitude cusps have been investigated by relatively few spacecraft: Hawkeye (e.g. Farrell and Van Allen, 1990; Fung et al., 1997; Eastman et al., 2000), HEOS-1 and -2 (e.g. Hedgecock and Thomas, 1975; Haerendel et al., 1978; Dunlop et al., 2000), Prognoz-7 (Lundin, 1985), Polar (Russell, 2000) and Interball (Zelenyi et al., 1997; Sandahl et al., 1997). In particular, HEOS, Prognoz-7, Hawkeye and Interball have sampled regions around and beyond the magnetopause boundary, with great interest in the effect of external driving forces on the position and geometry of the high- latitude, high-altitude cusp region. Eastman et al. (2000) and Merka et al. (2000) have showed the magnetopause to be indented in this region (contradicting the view of Zhou and Russell, 1997), as suggested from models (e.g. Spreiter et al., 1968; Boardsen et al., 2000). Using Interball-1 statistics, Savin et al. (1998) found this indentation to be $\sim 2 R_{E}$, on average, and Merka et al. $(1999,2000)$ reported the highaltitude cusp to occupy a broader region (in latitude and longitude) than expected from low-latitude observations, in addition to the effect of a non-negligible IMF $B_{X}$ component on the cusp location. These recent reports (Merka et al., 1999, 2000; Eastman et al. 2000) conclude that the major parameters affecting the cusp (and associated boundary layers) at high-latitude are the dipole tilt and the solar wind pressure, with IMF effects as secondary. Eastman et al. (2000) found 
the invariant latitude of the cusp to be greatest with a large positive dipole tilt (dipole located on the Sun - facing hemisphere) and the solar wind pressure to decrease the radial location of the cusp by $\sim 1200 \mathrm{~km}$ per nP. The cusp crossings from these satellites have provided a greater understanding of the dynamics and geometry of the region, as described in Haerendel et al. (1978); Farrell and Van Allen (1990); Kessel et al. (1996); Chen et al. (1997); Dunlop et al. (2000) and Eastman et al. (2000). However, there are still remaining questions related to the cusp: the persistence and stability of the cusp structure (e.g. Cowley et al., 1991); the geometry of the cusp (Fritz et al. 2002) and the reaction of the magnetosheath flow to this geometry (Cargill, 1999; Taylor and Cargill, 2002); the nature of the cusp/magnetosheath interface (Lavraud et al., 2002; Savin et al., 2004). The question of spatial/temporal ambiguity is a common problem with single spacecraft data, and multi-spacecraft observations have shown to be useful in examining and distinguishing between spatial and temporal phenomenon (Trattner et al., 2003). The magnetosheath-cusp interface is still a region of difficulty with respect to definition (Lavraud et al., 2002; Savin et al., 2004), possibly due to ambiguity in similar signatures being interpreted differently (Eastman, 2000; Dubinin et al., 2002).

The Cluster mission has provided a unique opportunity to investigate the local scale structure of the cusp and its surrounding regions. First results from the initial high-altitude cusp phase of the mission (January-April 2001) have demonstrated some of the new science that is available, from multipoint measurement techniques to state-of-the-art instrument capabilities (e.g. Cargill et al., 2001; Bosqued et al., 2001; Krauklis et al., 2001; Lavraud et al., 2002; Owen et al., 2001 and Taylor et al., 2001). Also, with the addition of groundbased instruments, the real multipoint, multi-instrument capability of the mission has been revealed (e.g. Lockwood et al., 2001a,b; Opgenoorth et al., 2001; Amm et al., 2003).

The present study focuses on an event during this first cusp phase, where we utilise the four-point measurement capabilities of Cluster to examine the dynamics of the high-altitude cusp. Using a combination of electron, magnetic field, and ion measurements from the Plasma Electron And Current Experiment (PEACE), fluxgate magnetometer (FGM), and Cluster Ion Spectrometer (CIS) instruments, we investigate the morphology and dynamic nature of the cusp. We note that, as in the work by Fung et al. (1997), we encompass the various terms related to the cusp region, such as "cleft", "entry layer", etc., and refer to a general "exterior cusp" as the region observed at high altitudes, unless otherwise stated.

\section{Instruments}

The previous missions investigating the high-altitude cusp described above had rather low-resolution plasma and magnetic field detectors. The HEOS full energy spectrum $(100 \mathrm{ev}-40 \mathrm{keV})$ was taken every $256 \mathrm{~s}$ and a single point magnetic field vector every 32-48 s (Hedgecock and Thomas, 1975). Hawkeye's full energy spectrum was taken every $210 \mathrm{~s}$, the magnetic field instrument having a resolution $\sim 1.89 \mathrm{~s}$ (Chen et al., 1997). The INTERBALL-TAIL ELECTRON instrument improved on this, providing $2 \mathrm{~min}$ resolution (Zelenyi et al., 1997) over a $10 \mathrm{ev}$ to $22 \mathrm{keV}$ range with magnetic field vector measurements provided at a rate of $4 \mathrm{~Hz}$ (Federov et al., 2000). In comparison, on board Cluster, the plasma instruments provide much higher time and energy resolution than their predecessors (PEACE: $\sim 0.6 \mathrm{ev}$ to $\sim 26 \mathrm{keV}$ and CIS: $5 \mathrm{ev} / \mathrm{q}$ to $38 \mathrm{keV} / \mathrm{q}$, both with 4-sec resolution) which, along with the Fluxgate Magnetometer (FGM) (magnetic field vector measurements at the rate of $12 \mathrm{~Hz}$ ), enable the examination of much smaller-scale plasma and magnetic field phenomena.

\subsection{PEACE}

The Plasma Electron and Current Experiment (PEACE) on board the Cluster spacecraft consists of two sensors, HEEA (High Energy Electron Analyser) and LEEA (Low Energy Electron Analyser), mounted on diametrically opposite sides of the spacecraft. They are designed to measure the threedimensional velocity distributions of electrons in the range $0.6 \mathrm{ev}$ to $\sim 26 \mathrm{keV}$. In standard mode HEEA measures the range $35 \mathrm{ev}$ to $26 \mathrm{keV}$ and LEEA $0.6 \mathrm{ev}$ to $1 \mathrm{keV}$, although either can be set to cover any subset of the energy range. Onboard moment calculations are made for energies $>10 \mathrm{ev}$, with the subsequent energy range divided into 3 regions depending on energy. Due to the sensor mounting geometry, the top and bottom energy ranges have 4-s resolution (measured only by HEEA and LEEA respectively) while the overlap energy range (measured by both sensors) has 2 -s resolution. For further instrument information, the reader is referred to Johnstone et al. (1997) and Szita et al. (2001). Data presented in this study uses the most up-to-date calibrations.

\subsection{FGM}

The fluxgate magnetometer (FGM) experiment on Cluster consists of two sensors on each spacecraft, together with their on board data processing units (Balogh et al., 1997, 2001). Currently, the primary sensor is the outboard sensor and during normal operation, the instruments are commanded to provide primary sensor data at $22.4 \mathrm{~Hz}$ in the spacecraft normal mode and $67 \mathrm{~Hz}$ in spacecraft burst mode. These data are filtered and re-sampled on board from an internal digital sampling rate of $202 \mathrm{~Hz}$. The magnetometers were operating in burst mode during the event presented below. Here, we have used both spin averages of the data (overview) and sub-second data $(12 \mathrm{~Hz})$ where appropriate for the boundary analysis. The data are believed to be inter calibrated to at least $0.1 \mathrm{nT}$ accuracy overall.

\subsection{CIS}

The Cluster Ion Spectrometry (CIS) experiment consists of two different instruments: a COmposition and DIstribution Function analyzer (CIS1/CODIF), giving the mass per charge composition with medium $\left(22.5^{\circ}\right)$ angular resolution, 
and a Hot Ion Analyser (CIS2/HIA), which does not offer mass resolution but has a better angular resolution $\left(5.6^{\circ}\right)$. The instruments measure the full, three-dimensional ion distribution $(\mathrm{H}+, \mathrm{He}+, \mathrm{He}++$, and $\mathrm{O}+)$ each spin $(4 \mathrm{~s})$, from 5 ev/q to about $38 \mathrm{keV} / \mathrm{q}$. The data shown here is transmitted at spin resolution from the HIA instrument, where all ions are measured. Pitch angle data are presented in the spacecraft frame. The CIS instruments on spacecraft 2 are unfortunately inoperable. Further information on the CIS instrument can be found in Rème et al. (2001).

\subsection{WHISPER}

The WHISPER (Waves of HIgh frequency and Sounder for Probing Electron density by Relaxation) instrument on board Cluster has 2 functions: Eq. (1): the resonance sounder, which provides absolute measurement of the total plasma density within the range $0.2-80 \mathrm{~cm}^{-3}$ by actively stimulating and detecting the resonances of the ambient plasma. Equation (2): passive operation, which provides a survey of natural emissions in the $2-80 \mathrm{kHz}$ range. WHISPER is part of the Wave Experiment Consortium (WEC), which consists of five instruments designed to measure electric and magnetic field fluctuations and plasma density structure in the solar wind and magnetosphere. WHISPER data is presented at spin resolution $(4 \mathrm{~s})$. More information on WHISPER can be found in Décréau et al. (1997) and (2001), and Pederson et al. (1997) for WEC.

\subsection{RAPID}

In this study we utilise data from the Imaging Electron Spectrometer (IES) (part of the Research with Adaptive Particle Imaging Detector (RAPID)). This instrument measures electron fluxes in 6 energy channels ranging from $42-453 \mathrm{keV}$, and data is presented in this paper at spin resolution (4s). Further information can be found in Wilken et al. (1997) and (2001).

\subsection{Observations}

Figure 1 shows data from the PEACE, FGM, CIS, RAPID and WHISPER instruments on board the Cluster spacecraft for the period 03:50 to 06:20 UT on the 26 February 2001, along with corresponding ACE magnetic field data. The dashed vertical lines represent the times of well-defined boundaries between different plasma populations observed at Cluster. During this time the four Cluster spacecraft were outbound, as indicated by the GSM (Geocentric Solar Magnetic) coordinates along the bottom axis in Fig. 1, with an average separation of $\sim 600 \mathrm{~km}$. MLT and invariant latitude values $\left(11.6-12.4\right.$ and $\left.82-78^{\circ}\right)$ are consistent with the spacecraft being in the cusp region, as described by Fung et al. (1997). Panel 1 shows the IMF data from the ACE MFE instrument (Smith et al., 1997) plotted with a lag time of $85 \mathrm{~min}$, calculated by using a simple convective approximation, where the average solar wind velocity is $\sim 293 \mathrm{~km} / \mathrm{s}$ and the distance from ACE to Cluster along the Sun-Earth line is $\sim 229 R_{E}$, although we note that this approximation is subject to some variation (i.e. Weimer et al., 2002). Indeed, when comparing ACE and Cluster magnetic field data during Cluster's magnetosheath passage (after 06:15 UT) we see variations in the lag times of $\sim 10 \mathrm{~min}$. Panel 2 shows a comparison of the clock angle between ACE and Cluster. Ion measurements from the SWEPAM instrument on board ACE during this period are less reliable than usual (R. Skoug, private communication, 2002) due to somewhat low flow speeds, so no accurate determination of the solar wind pressure can be made. Panel 3 shows FGM magnetic field data in a similar format to panel 1. Panels 4,5 and 6 show RAPID, PEACE electron and CIS ion energy time spectrograms (averaged over all look directions, in units of differential energy flux), respectively. Panel 7 shows CIS ion velocity in GSM coordinates. Panel 8 shows plasma density derived from the WHISPER instrument and partial electron densities derived from PEACE from 2 different energy ranges: the TOP region $(>1000 \mathrm{keV})$ and the OVERLAP region covering $35-1000 \mathrm{eV}$. These two ranges give a good indication of the different ambient plasma populations: the TOP region covering typical magnetospheric electron energies $(\sim \mathrm{keV})$ and the OVERLAP region covering the lower energy, cusp/magnetosheath electrons ( $\sim$ tens - hundreds ev). We note that the PEACE partial moments have been slightly re-scaled to fit onto the same scale.

At the beginning of the interval, the spacecraft are located in the northern lobes/plasma mantle and observe characteristically low plasma densities $\left(\mathrm{n} \sim 0.1 \mathrm{~cm}^{-3}\right)$ and a large and negative $B_{z}$. At around 04:02 UT (near boundary 1) the spacecraft observe spectral properties characteristic of an injection of magnetosheath-like plasma, with electron (ion) energies up to $\sim 200(\sim 1000) \mathrm{ev}$, along with an increase in plasma density and increased magnetic fluctuations. These plasma conditions are consistent with observations of the cusp region (Rae et al., 2001). We note that we have marked an additional boundary at 1a, as the initial boundary Eq. (1) is complicated by spacecraft potential contamination, due to the active spacecraft potential control (ASPOC) (Torkar et al., 2001) on Cluster 1 being inoperable. As a result of this, the PEACE lower energy data from Cluster 1 is highly susceptible to contamination by spacecraft electrons (Szita et al., 2001), and is most predominant in the OVERLAP range. The effect of this can be seen during the transition from lobe to cusp in the OVERLAP density plot in panel 8 , Fig. 1, where between $\sim 03: 58$ and 04:02 UT there is an increase in OVERLAP density caused by enhanced spacecraft potential. Boundary $1 \mathrm{a}$ is defined by a clear inflection in the electron moments. At around 04:41 UT the ion bulk velocity increases and several injections are detected until $\sim 05: 13$ UT (boundary 2), with the arrival of a region of much higher energy electrons and ions (up to tens $\mathrm{keV}$ ), associated with a drop-out in the lower energy populations, as indicated by the partial densities in Panel 8 . We note that during the period 04:41-05:13 UT, the ions become more unidirectional, aligning with the field direction, i.e. $V_{z}$ is negative. At this time the perpendicular ion flow magnitude is 


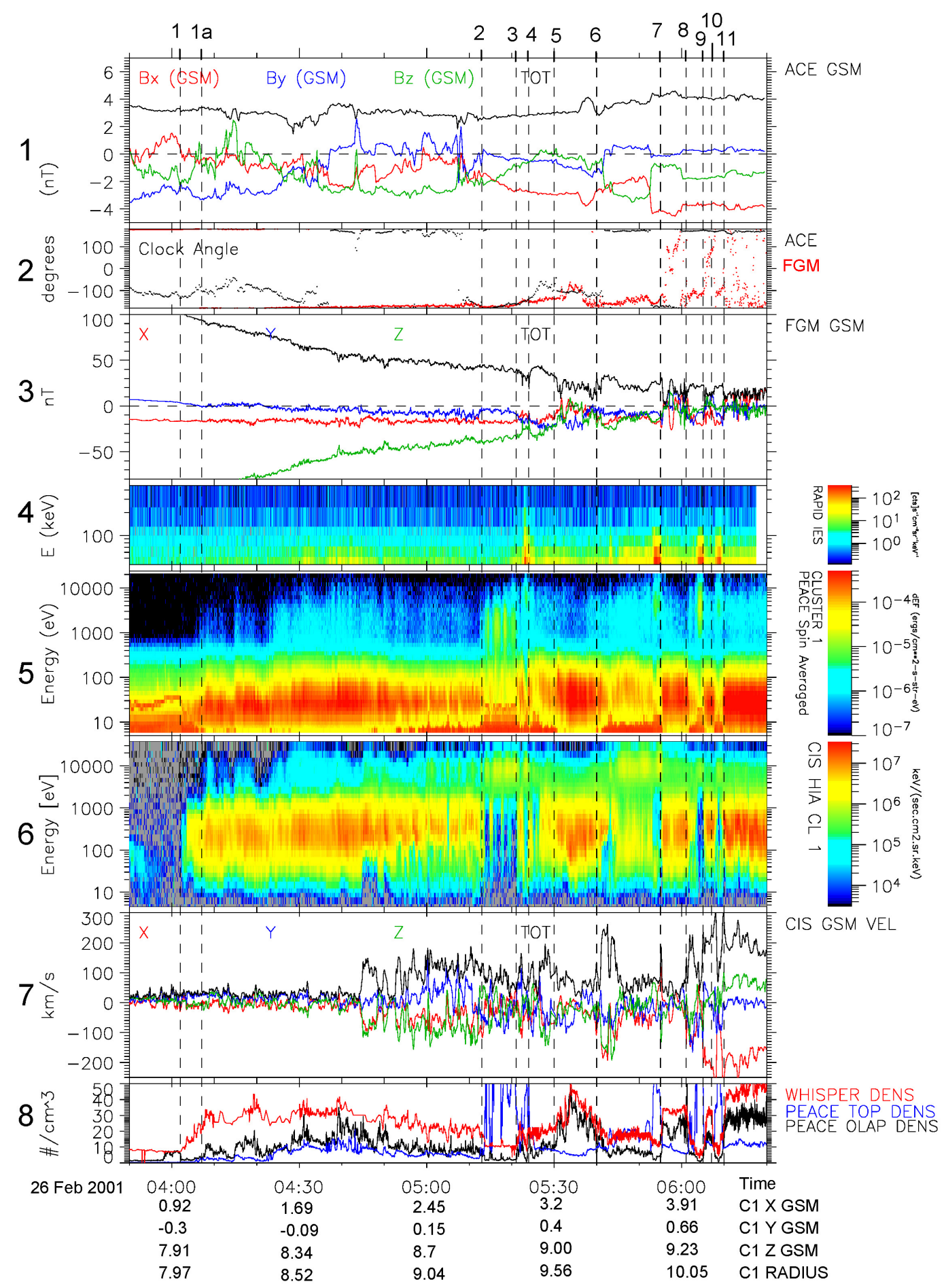

Fig. 1. We note that all Cluster data is presented in 4-s spin resolution, unless otherwise stated. Panel 1 shows ACE magnetic field data in the GSM coordinate frame, $\mathrm{x}, \mathrm{y}, \mathrm{z}$ and magnitude. ACE is at position $\sim(232,-40,-5) R_{E} \mathrm{GSM}$ at this time. MFE values are Level 216 -s resolution with a 85-min lag applied. Panel 2 shows a comparison of ACE (black dots) and Cluster (red dots) magnetic field clock angles, where clock angle is $\arctan \left(\mathrm{B}_{Y} / \mathrm{B}_{Z}\right)$. Panel 3 shows FGM magnetic field data from Cluster 1 in GSM coordinates. Panels 4-6 show RAPID IES electron, PEACE electron and CIS HIA ion data in the form of energy-time spectrograms. Flux units are \#/ $\mathrm{cm}^{2} \mathrm{ssrkeV}$, ergs $/ \mathrm{cm}^{2} \mathrm{ssreV}$ and $\mathrm{keV} / \mathrm{cm}^{2}$ ssrkeV, respectively. Panel 7 shows CIS ion velocity in GSM coordinates. Finally, Panel 8 shows PEACE derived densities (TOP in blue, scaled by 200 and OVERLAP in black) and WHISPER derived densities in red. The dashed, numbered vertical lines represent the boundaries discussed in Table 1. 
comparable with the field-aligned flow (not shown), suggesting enhanced convection is occurring, possibly in association with the southward IMF at this time. The region between boundary 2 and 3 has a significant perpendicular pitch angle component (not shown), characteristic of a dayside trapped plasma population, dayside plasma sheet (DPS), on closed field lines (Cowley and Lewis, 1990). After boundary 3 Cluster briefly re-enters a cusp/magnetosheath-like population, but then briefly re-enters the DPS (just before boundary 4). In panel 4 , we see that this region has a higher energy than the previous DPS encounter. This energy change could be related to electron drift from the nightside plasma sheet, with the higher energy particles under the influence of gradient drift being found at larger radial distances, such that Cluster is sampling a "deeper" (lower L shell) region between 05:15-05:21 UT and a magnetospheric region much closer to the cusp boundary later on. After boundary 4, there is a succession of cusp/magnetosheath-like plasma encounters, delimited by boundaries 5 and 6, 7 and 8 and 9 and 10, with associated enhanced magnetic field fluctuations. These regions, (boundary pairs: 5-6, 7-8, and 9-10) are interrupted by boundary layer regions containing a mixture of high DPSlike energy plasma and lower energy (lower flux) magnetosheath like plasma (e.g. between boundaries 6-7) and also more defined DPS encounters, i.e. just prior to boundaries 7, 9 and 11. Exit into the magnetosheath occurs after boundary 11 , where the magnetosheath appears highly turbulent, as one can see from the comparison of clock angles in panel 2. The next section examines the dynamics of these boundaries.

\section{Boundary analysis}

3.1 PEACE timing analysis (PTA) and FGM discontinuity analyser (DA) techniques

The tetrahedron configuration of the four Cluster spacecraft enables the three-dimensional study of small-scale structures in space plasma for the first time. As has been pointed out by Dunlop and Woodward (2000) (and earlier papers referenced therein), the dynamics of well-defined magnetic boundaries, for example, can be determined using combined inter-spacecraft timing, position information and boundary normal analysis (the discontinuity analyser, DA). With the additional assumption (which may not be valid) that the boundary motion is approximately constant, we can also explicitly calculate the constant speed along the boundary normal, and corresponding direction, from the timing and position information alone (Russell et al., 1983). Such techniques have been utilised on initial Cluster PEACE plasma data, i.e. Owen et al. (2001) and Taylor et al. (2001), in particular using relative changes in the density moments. Following Harvey (2000), if $\mathrm{t}_{\alpha}$ is the time that the boundary is observed by a spacecraft $\alpha, 1 \leq \alpha \leq 4$, located at $\mathrm{r}_{\alpha}$, then during the time $\mathrm{t}_{\alpha}-\mathrm{t}_{3}$ the plane of the discontinuity moves along the normal
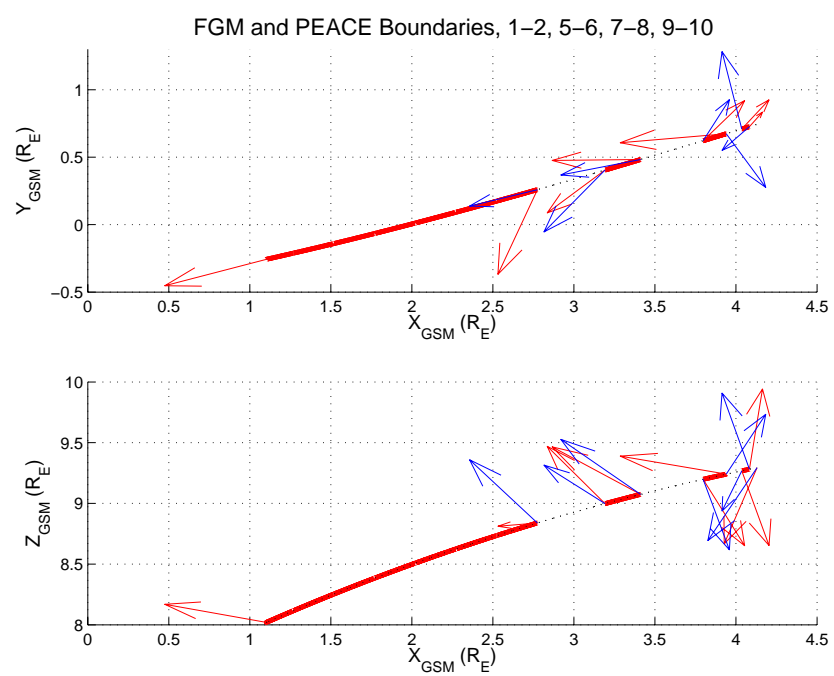

Fig. 2. Projection on Cluster orbit trajectory of boundary norma pairs from cusp crossings, 1a-2, 5-6, 7-8 and 9-10, in GSM coordinates. The thick red lines indicate the region of "cusp" bounded by the boundary pair. The red arrows are unit normals derived by PTA and the blue arrows normals from DA.

direction $\mathrm{V}\left(\mathrm{t}_{\alpha}-\mathrm{t}_{3}\right)$ which is equal to the projection of the separation distance $r_{\alpha}-r_{3}$ onto $\hat{n}$,

$\left(r_{\alpha}-r_{3}\right) \hat{n}=V\left(t_{\alpha}-t_{3}\right)$

We introduce the vector

$m=\frac{\hat{n}}{V}$

such that Eq. (1) may be written

$D m=T$,

where $D$ is the $3 \times 3$ matrix (not a tensor) defined by

$D=\left(r_{1}-r_{3}, r_{2}-r_{3}, r_{4}-r_{3}\right)$

and $T$ is the linear array

$T=\left(\begin{array}{l}t_{1}-t_{3} \\ t_{2}-t_{3} \\ t_{4}-t_{3}\end{array}\right)$

This set of equations is solved by finding the inverse matrix $D^{-1}$ such that

$D^{-1} D=$ I= unit operator $\left(=\delta_{i k}\right)$

hence $\boldsymbol{m}$ is found, ( $\delta$ is Kronecker delta)

$\mathrm{m}=D^{-1} T$

Note that $|D| \neq 0$ (i.e. $D^{-1}$ must exist, a condition which is satisfied if, and only if, the four spacecraft are not coplanar).

In this paper we attempt to engage the problem of errors in the calculation of the normal from this method. If $\delta \mathrm{r}$ is the error in spacecraft position and is propagated into the calculation of $D$ as $\delta D$, along with $\delta$ t as the time error from 

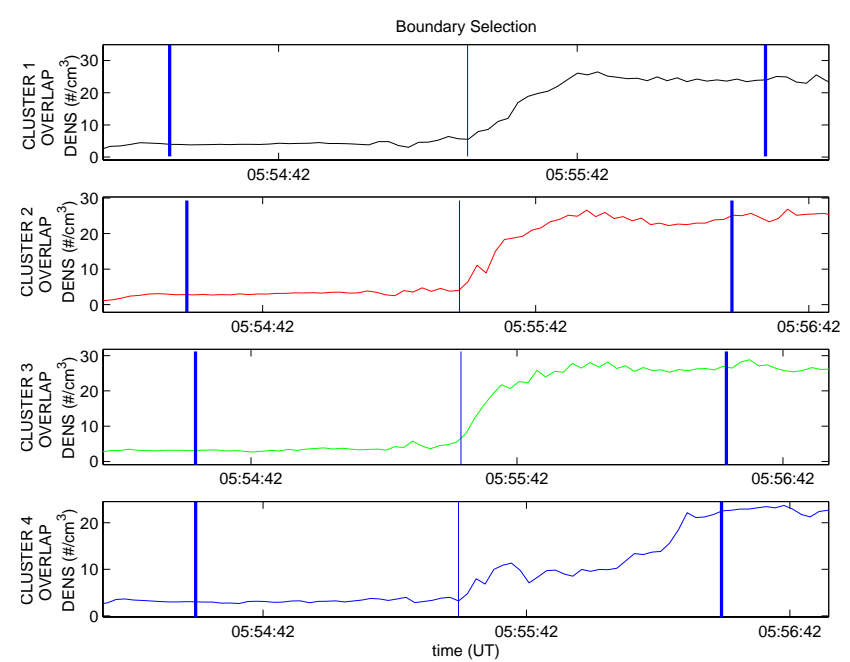

Fig. 3. Four spacecraft PEACE OVERLAP (35-1000 eV) density data (spacecraft 1 in top panel through to 4 in bottom) used in the PTA technique. The chosen boundary position is indicated by the central thin vertical line, with a correlation window of $\sim \pm 60 \mathrm{~s}$ marked by thicker pairs of vertical lines.

the measurements due to instrument resolution, then we can write the fractional error in $\boldsymbol{m}$ in the $\lambda$ - direction as

$$
\left(\frac{\delta m}{m}\right)_{\lambda}^{2}=\left(\frac{\delta D^{-1}}{D^{-1}}\right)_{\lambda}^{2}+\left(\frac{\delta t}{t}\right)_{\lambda}^{2}
$$

From this we can then determine an error in the boundary normal $\delta \boldsymbol{n}$. In this paper we have used $\delta \mathrm{r}=10 \mathrm{~km}$ and $\delta \mathrm{t}=2$ or $4 \mathrm{~s}$, depending on whether we use overlap or top density moments.

To quantify the identification of boundaries in the PEACE data we have used a cross correlation technique in conjunction with identifying a boundary by eye. Following Press et al. (1999), we calculate the cross correlation of two data samples which gives a maximum correlation coefficient at a particular lag or time difference between the two samples. To apply this technique to the four spacecraft data from PEACE, we start by roughly selecting the boundary at each spacecraft we wish to perform the timing analysis on, an example of which is given in Fig. 3, where we have indicated the chosen boundary with a central, thin vertical line. We then take a window $\pm T$ (where $T$ is $\sim 60 \mathrm{~s}$ ) around each selected boundary time (thicker blue lines on either side of central blue line in Fig. 3) and correlate this windowed data segment from each spacecraft with the reference spacecraft, in this case spacecraft 3 . The correlation coefficient, $\rho$, quantifies the level of correlation between the spacecraft pairs, with the lowest $\rho$ found to be 0.74 . In this paper we shall refer to the technique as PEACE timing analysis or PTA.

We note that the dominant term in Eq. (7) is from the instrument $(\delta \mathrm{t})$, which greatly effects the accuracy of the normal determination when $\boldsymbol{T} \sim \delta \mathrm{t}$. However, we re-iterate that this method of boundary normal determination assumes a planar boundary at constant velocity. Such assumptions can be tested using the Discontinuity Analyser (DA) technique (Dunlop and Woodward, 2000), where single spacecraft methods (minimum variance of the magnetic field for example) can determine the planarity of the boundary as it passes each spacecraft (recently demonstrated in detail by Dunlop et al., 2002) and for a reasonably planar boundary, an attempt to examine the level of acceleration. For brevity we refer the reader to Dunlop and Woodward (2000) and Dunlop et al. (2002) for further information on the DA technique.

\subsection{Application}

Figure 2 and Table 1 summarises the PEACE timing analysis (PTA) and DA results carried out on the period of data shown in Fig. 1. In Fig. 2 we have projected the unit normals of the "cusp" crossings pairs on the orbit path in the $\mathrm{x}-\mathrm{y}$ and $\mathrm{x}-\mathrm{Z}$ GSM plane. In all, we focus on four cusp crossings corresponding to the boundary pairs, $1 \mathrm{a}-2,5-6,7-8,9-10$ and the exit into the magnetosheath at 11, where in Fig. 2 the thick red lines denotes the region of the cusp, bounded by each boundary normal pair, along the spacecraft trajectory. The red arrows show the PTA derived normals and blue arrows denote DA derived normals. We note that we have used the boundary pair 1a-2 to represent the first cusp crossing due to the contamination effects discussed in the observation section above. Because of this contamination, we were unable to utilize the correlation technique to determine boundary 1 and instead used a more "by eye method". For boundary 1a, which was slightly within the cusp, we were able to perform the PTA from then on. The remaining crossings represent the un-paired boundaries as indicated in Fig. 1. In general, boundary choice was determined by the identification of a boundary in either FGM or PEACE and searching with the other instrument for a boundary signature as close as possible to the other. The upper section of Table 1 shows the PTA information, with the boundary observation time at each spacecraft followed by the derived normal for each boundary, along with the boundary velocity, error in the normal components and correlation coefficient of the three spacecraft pairs (with SC-3 as the reference spacecraft). The shaded columns in Table 1 represent the boundaries that we were unable to determine using the DA technique. The lower section of Table 1 shows the results from the DA technique, indicating the boundary number, average normal direction, DA calculated velocity, relative time and relative velocity $(\Delta \mathbf{R} . \mathbf{n} / \Delta \mathrm{t}(1,2,4))$ across the tetrahedron (with spacecraft 3 as the reference spacecraft). We note that the single spacecraft normals, calculated using a minimum variance technique on the magnetic field data, show good agreement with respect to the planarity of the boundaries across the tetrahedron, confirming our planarity assumption for the timing technique described above (PTA). However, the relative velocities in the table in some cases indicate large accelerations between subsequent spacecraft observations. This matter is discussed further below, with respect to the PTA-DA comparison.

For the first crossing in Table 1 (boundaries 1a-2), the boundaries indicate a straightforward crossing of the cusp 
SUMMARY OF PEACE TIMING RESULTS

\begin{tabular}{|c|c|c|c|c|c|c|c|c|c|c|c|c|}
\hline BOUNDARY & 1 & $1 \mathrm{a}$ & 2 & 3 & 4 & 5 & 6 & 7 & 8 & 9 & 10 & 11 \\
\hline Observation time at CLUSTER 1 (UT) & 04:02:05 & 04:07:49 & $05: 13: 47$ & $05: 21: 19$ & 5:23:42 & $05: 30: 32$ & 05:39:57 & $05: 55: 20$ & $06: 01: 25$ & $06: 05: 13$ & $06: 07: 37$ & 06:09:59 \\
\hline Observation time at CLUSTER 2 (UT) & 04:02:24 & 04:07:49 & 05:13:49 & 05:21:41 & 5:23:36 & 05:30:24 & 05:39:52 & 05:55:25 & 06:01:23 & 06:05:34 & 06:07:19 & $06: 10: 22$ \\
\hline Observation time at CLUSTER 3 (UT) & 04:01:58 & 04:07:13 & $05: 13: 45$ & $05: 21: 46$ & 5:23:34 & $05: 30: 15$ & 05:39:48 & 05:55:29 & 06:01:17 & $06: 05: 42$ & $06: 07: 26$ & 06:10:09 \\
\hline Observation time at CLUSTER 4 (UT) & 04:03:40 & 04:08:17 & 05:13:48 & $05: 21: 25$ & $5: 23: 46$ & 05:30:23 & 05:39:56 & $\begin{array}{l}05: 55: 27 \\
\end{array}$ & 06:01:28 & 06:05:42 & 06:07:15 & $06: 10: 29$ \\
\hline $\mathrm{n}_{\mathrm{x}}$ & -0.44 & -0.93 & -0.36 & 0.71 & -0.8 & -0.53 & -0.81 & 0.38 & -0.97 & 0.25 & 0.12 & -0.3 \\
\hline $\mathrm{n}_{\mathrm{Y}}$ & 0.88 & -0.29 & -0.93 & -0.29 & 0.53 & -0.47 & -0.01 & 0.44 & -0.1 & 0.32 & 0.16 & -0.22 \\
\hline $\mathrm{n}_{\mathrm{z}}$ & -0.12 & 0.22 & -0.04 & -0.65 & 0.28 & 0.7 & 0.58 & -0.81 & 0.22 & -0.91 & 0.98 & -0.93 \\
\hline $\mathrm{V}_{\text {MAX }}$ & 2.8 & 7.5 & 98 & 16.9 & 38.5 & 26.7 & 53 & 53 & 53.7 & 16 & 27.1 & 18.1 \\
\hline$\%$ error in $n_{x}$ & 7.2 & 19.8 & 151 & 15 & 43 & 18 & 20 & 31 & 51.2 & 28 & 59 & 21 \\
\hline$\%$ error in $\mathrm{n}_{\mathrm{Y}}$ & 3.5 & 13.6 & 109 & 9 & 56 & 11 & 59 & 20 & 286 & 9 & 19 & 15 \\
\hline$\%$ error in $n_{z}$ & 5.8 & 32.8 & 266 & 20 & 34 & 22 & 45 & 36 & 41 & 14 & 20 & 14 \\
\hline Corr-coef for s/c pair 3-1 & 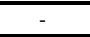 & 0.84 & 0.93 & 0.74 & 0.87 & 0.84 & 0.84 & 0.985 & 0.899 & 0.91 & 0.955 & 0.97 \\
\hline Corr-coef for s/c pair 3-2 & - & 0.87 & 0.96 & 0.88 & 0.88 & 0.91 & 0.94 & 0.995 & 0.955 & 0.96 & 0.955 & 0.975 \\
\hline Corr-coef for s/c pair 3-3 & - & 1 & 1 & 1 & 1 & 1 & 1 & 1 & 1 & 1 & 1 & 1 \\
\hline Corr-coef for s/c pair 3-4 & - & 0.88 & 0.85 & 0.85 & 0.89 & 0.77 & 0.89 & 0.84 & 0.97 & 0.97 & 0.95 & 0.975 \\
\hline
\end{tabular}

SUMMARY OF FGM DISCONTINUITY ANALYSER RESULTS

\begin{tabular}{|c|c|c|c|c|c|c|c|c|c|c|}
\hline \multirow{3}{*}{$\mathrm{n}_{\mathrm{av}}$} & $\mathrm{n}_{\mathrm{x}}$ & -0.62 & 0.74 & -0.56 & -0.73 & 0.24 & 0.36 & -0.18 & -0.25 & -0.45 \\
\hline & $\mathrm{n}_{\mathrm{Y}}$ & 0.11 & 0.35 & -0.68 & -0.17 & 0.45 & -0.59 & 0.85 & -0.26 & -0.07 \\
\hline & $\mathrm{n}_{\mathrm{Y}}$ & 0.78 & -0.57 & 0.47 & 0.67 & -0.86 & 0.73 & -0.49 & 0.93 & -0.89 \\
\hline \multicolumn{2}{|c|}{$\Delta \mathbf{R} \cdot \mathbf{n} / \Delta \mathrm{t}$ (Velocity, $\mathrm{km} / \mathrm{s})$} & 78.0 & 120.0 & 27.0 & 47.0 & 17.0 & 26.0 & 19.0 & 21.0 & 25.6 \\
\hline \multicolumn{2}{|c|}{$\Delta \mathrm{t} 3-1$} & 4.0 & -6.1 & 15.9 & 19.1 & -12.1 & 14.0 & -16.3 & 15.8 & -18.0 \\
\hline \multicolumn{2}{|c|}{$\Delta \mathrm{t} 3-2$} & 3.3 & -5.7 & 6.3 & 5.3 & -2.8 & -2.0 & -14.3 & -6.2 & 3.1 \\
\hline \multicolumn{2}{|c|}{$\Delta \mathrm{t} 3-4$} & 4.0 & -2.0 & 10.8 & 13.7 & 24.8 & $\begin{array}{l}-8.6 \\
\end{array}$ & 6.2 & -13.4 & 19.8 \\
\hline \multicolumn{2}{|c|}{$\Delta \mathbf{R} \cdot \mathbf{n} / \Delta \mathrm{t}(1)(\mathrm{km} / \mathrm{s})$} & -119.4 & 73.1 & -28.7 & -26.1 & 36.7 & 14.4 & -15.6 & -28.1 & -9.1 \\
\hline \multicolumn{2}{|c|}{$\Delta \mathbf{R} \cdot \mathbf{n} / \Delta \mathrm{t}(2)(\mathrm{km} / \mathrm{s})$} & -51.3 & 64.3 & -48.7 & -34.8 & 28.5 & 24.4 & -10.6 & 3.4 & -44.0 \\
\hline \multicolumn{2}{|c|}{$\Delta \mathbf{R} \cdot \mathbf{n} / \Delta \mathrm{t}(4)(\mathrm{km} / \mathrm{s})$} & -63.3 & 222.6 & -25.3 & -25.8 & 1.0 & 47.2 & -37.2 & -1.6 & -23.7 \\
\hline
\end{tabular}

Table 1. Results from PTA and DA. Columns indicate the boundary number from Fig. 1. Boundary 1a is described in the text. The upper section of the table shows the times of the boundary observation at each spacecraft. Below this are the results of the PTA: the components of the normal and the speed of the boundary. Below this are the percentage errors in each normal component followed by the correlation coefficients of the boundary at each spacecraft with spacecraft 3. The lower table shows the DA results. The first 3 rows show the "average" normal direction, followed by the speed of this normal. Below this are 3 inter-spacecraft time differences of the boundary, i.e. $\Delta \mathrm{t} 3-1$ is the time taken for the boundary to have traveled from spacecraft 1 to 3 . Finally, the final three rows show the speed variations along the normal direction, all with respect to spacecraft 3, i.e. $\Delta \mathbf{R} . \mathbf{n} / \Delta$ t Eq. (1) $\mathrm{km} / \mathrm{s}$ is the boundary speed between Cluster 3 and 1 . Note, DA times are not shown but are as close to the PTA boundary times as the data allowed, again this is discussed in the text.

throat, with the initial boundary indicating entrance via the duskward (and slightly poleward) edge of the cusp, with the cusp boundary moving at $\sim 7 \mathrm{~km} / \mathrm{s}$. Indeed, the magnetic field orientation at this time (positive $B_{y}$ in Fig. 1) also suggests Cluster is on the duskward edge of the cusp at this time. For the boundary Eq. (2) corresponding to the cusp exit, we have results from both the DA and PTA technique, with both values broadly describing a similar exit normal direction, i.e. boundary is moving tailward. However, we have a rather large discrepancy in the $\mathrm{z}$ and (predominantly) y components. In this case the PTA errors are quite large as $\boldsymbol{T} \sim \delta$ t, as discussed previously. In addition, the relative velocity calculation from the DA is much larger between spacecraft 1 and 3 than the two other spacecraft pairs, suggesting boundary deceleration. With small relative times from the PEACE observations, along with the acceleration, the PTA derived normal appears unreliable, although it still shows a tailward component like the DA normal. In general, we can say that this first entry-exit pair describes a complete crossing of the cusp, from the dusk/poleward to the equatorward edge.

For the second cusp crossing (5-6), the orientation of these normals suggest that the cusp boundary moves across Cluster in the antisunward direction once again, although as there are no distinct lobe features in the plasma data, one must assume Cluster is in some cusp boundary layer with the $y$ component suggesting entry on the dawnward edge and exit at the dusk/equatorward edge. In this case the PTA and DA methods show good agreement, with strong tailward components and a similar reversal in the normal y component at entry and exit. The PTA errors are quite low for entry Eq. (5), but increase at the exit boundary Eq. (6) (due to small interspacecraft timings resulting in a much larger velocity), perhaps reflected in the difference in the y direction between the two exit normals. For the third crossing (7-8), the PTA and DA methods show reasonable agreement at entry (especially in the $\mathrm{X}-\mathrm{Z}$ plane). Looking at the relative velocities in the DA analysis in Table 1, we can see evidence of some deceleration at boundary 7 (cusp entry) from spacecraft pairs 13 and 23 to 34. In Fig. 3 we show this deceleration as observed in the PEACE density moments. Concentrating on the boundaries at each spacecraft, indicated by the central vertical line, we see the sharp boundary gradients at spacecraft 1 , 2 and 3 in contrast to the much shallower gradient at spacecraft 4 , possibly reflecting a change in speed of the passage of the boundary over the spacecraft. In contrast the exit boundary appears to accelerate (Table 1), with less agreement with 


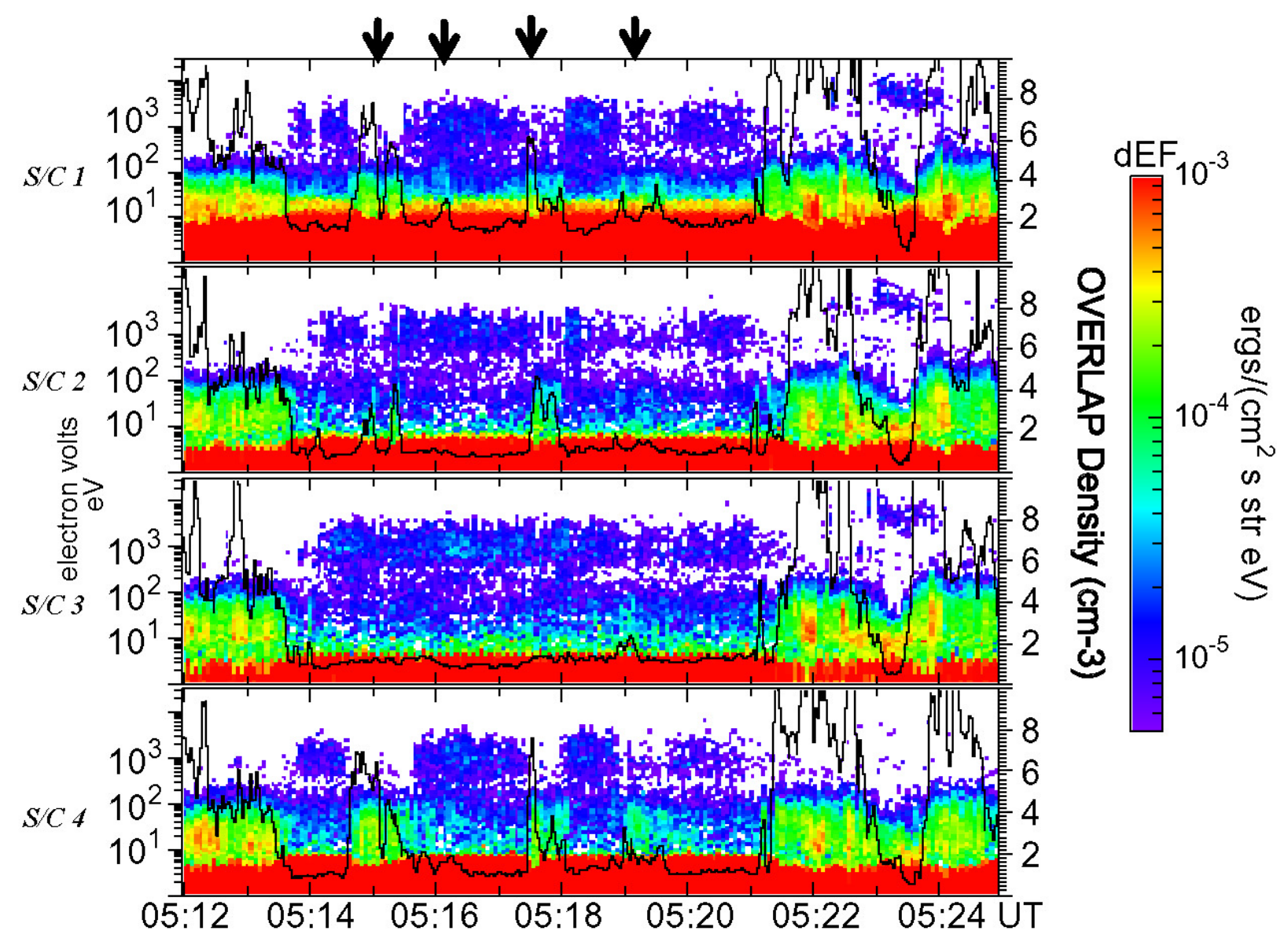

Fig. 4. Top panel shows Cluster 1 data through to Cluster 4 data in the bottom panel. Data is in energy-time spectrogram format, detailing the higher energy magnetospheric population, which is found predominantly in the perpendicular component of the pitch angle distribution. The arrows indicate the transient cusp/cusp boundary layer population appearances discussed in the text, where minimal spectral flux enhancements occur at Cluster 3, suggesting that the structures have a scale size of the order of the spacecraft separation. The black over-plotted line is PEACE density from the OVERLAP region, to accentuate the plasma transients.

the two derived normals and larger errors in the PTA. The high correlation coefficients in this case are misleading as the signature of this exit boundary was not very clean. Instead, it appears highly structured and quite diffuse (with a long shallow gradient), making boundary identification and hence boundary correlation at any scale quite difficult (not shown). In view of this we concentrate on the DA exit normal, where the entry-exit normal pair undergoes a significant $\mathrm{z}$ rotation, suggesting that Cluster is near the equatorward edge of the cusp, in close proximity to the boundary and thus making such a "skimming" entry-exit. For crossings 9-10, the spacecraft go back and forth through the boundary between the DPS and cusp/magnetosheath, apparently close to the region where the equatorward edge of the cusp turns towards the sub-solar region, as indicated by the rotation of the normal $z$-component from entry to exit. Finally, the spacecraft cross into the magnetosheath, with good agreement between the PTA and DA normals and velocities.

\section{Discussion}

From the boundary analysis of the cusp crossings described above we can begin to build a picture of the global structure and dynamics of the cusp. Up to boundary 3, and from boundary 7 through to 11 , the single spacecraft view of the spacecraft cutting across the cusp, skimming the equatorward edge of the cusp boundary layer and entering the magnetosheath is upheld. Indeed, during the transition between boundary 2 and 3, 4 spacecraft observations by the PEACE instrument further add to this picture of the tetrahedron skimming the equatorward edge of the cusp. In Fig. 4 we have plotted an energy-time spectrogram of the electrons from the parallel component of the pitch angle distribution of each spacecraft, s/c 1 at the top down to s/c 4 at the bottom. The OVERLAP density has been over-plotted in black to accentuate the cusp/magnetosheath plasma signatures. Overall, we can see the general structure of the region, comprised of high-energy DPS electrons (up to $10 \mathrm{keV}$ ), interspersed with transient lower energy, magnetosheath-like electrons $(<200 \mathrm{ev})$. Lundin et al. (2003) have examined a section of 

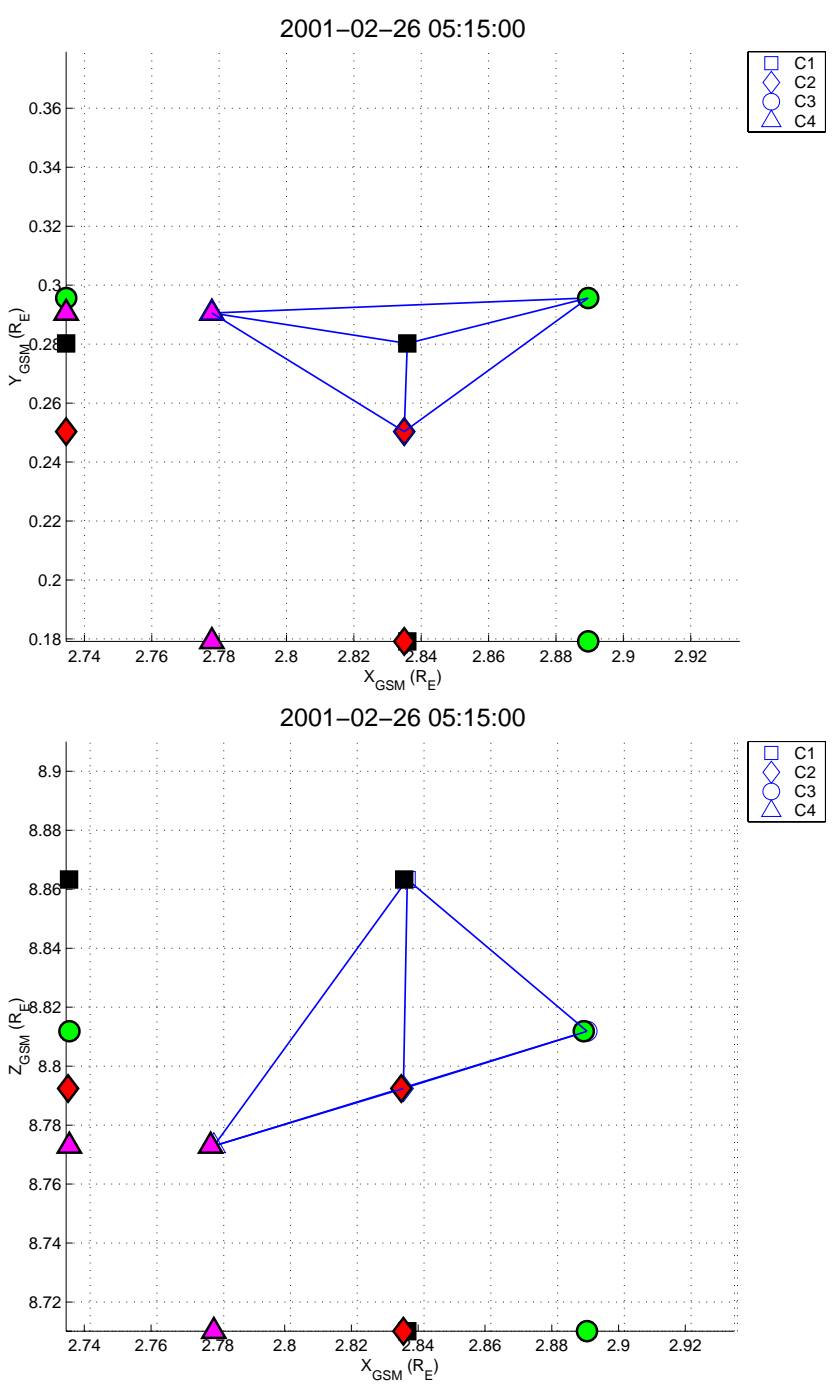

Fig. 5. The Cluster tetrahedron configuration around the time of the observations, with spacecraft positions in the (a) $x-y$ plane and (b) $\mathrm{x}-\mathrm{z}$ plane (GSM).

this period using Cluster ion and (single spacecraft) magnetic field measurements, describing transient plasma observations in terms of injected plasma clouds, "plasma transfer events" or PTE. In the current case we view the transients as brief encounters with the cusp boundary layer. In Fig. 4 we have indicated these transients with black downward arrows above the first panel, observed at s/c 1,2 and 4, centered around $\sim 05: 15,05: 16: 13,05: 17: 30$ and just after 05:19 UT. The lack of a signature in $\mathrm{s} / \mathrm{c} 3$ suggests spatial structure on a scale of less than the spacecraft separation, and this also means we cannot use the timing analysis described in Sect. 4. However, the use of the fourth spacecraft gives us a feel for the evolution of the populations through the ordered sequence of observations. The relative differences in flux, as well as the time of observation at each spacecraft, give us an idea of the gradient and scale of these plasma intrusions and are consistent with small-scale traversals of the boundary between the dayside magnetosphere/cusp boundary layer. Indeed, the or- dering of the observations of the transients by the tetrahedron is consistent with the general orientation of boundaries 2-3 (Fig. 1).

Figure 5 shows the orientation of the spacecraft configuration in GSM coordinates for this time period shown in Fig. 4. By considering the position of the spacecraft in combination with the boundary normal direction of the cusp exit (boundary 2 05:13 UT), it is clear that s/c 1 and 4 are almost aligned with, and closest to, the cusp boundary. Spacecraft 2 and 3 lie deeper into the dayside magnetosphere. Looking at the evolution with respect to the GSM $X$ direction we see that $\mathrm{s} / \mathrm{c} 4$ is more tailward than 1 , as well as lower in GSM $Z$. From this we conclude that the signature indicated by the first arrow is moving in the positive $X$ direction, perhaps with a slight negative $Z$, such that the transient is apparently moving sunward, consistent with a cusp/cusp boundary layer encounter. For the transient indicated by the second arrow, around $\sim 05: 16: 13 \mathrm{UT}$, the PEACE data suggests that the population could be remnant of the original signature at 05:15 UT. However, its observation by only s/c 1 and 4 allow for some inference of the origin of the population, again in this case the boundary arrives from the "rear" of the tetrahedron. The third arrow at $\sim 05: 17: 30$ UT, indicates a signature which has a slightly different ordering, but can still be associated with motion from the rear of the tetrahedron, in this case with a larger negative $Z$ component, as suggested from the first observation being at $\mathrm{s} / \mathrm{c} 1$. The signatures in the final transient are most coherent in s/c 1 and s/c 4, with a similar ordering to the previous transient, again suggesting motion in the positive $X$ and negative $Z$ directions. However, the fourth arrow indicates a signature starting at about 05:18:55 UT in s/c 3 suggests a more complicated structure, with some motion in the $\mathrm{x}-\mathrm{y}$ plane.

What spoils this "single-spacecraft" picture of Cluster cutting and skimming the dayside cusp boundary region, is the orientation of boundary 5 (and also boundary 4), which suggests the cusp is again equatorward of the spacecraft and moves tailward across the tetrahedron. Such an ordering of boundary normals suggests a highly dynamic cusp or disfigured cusp geometry, where both pairs of boundary normals (1-2 and 5-6) are ordered in a similar manner, such that the cusp appears to have crossed Cluster in the same direction, i.e. both cusps were entered on their poleward edge and were apparently convected tailward. Previous surveys of the highaltitude cusp region (e.g. Merka, 1999 and Eastman et al., 2000) reported that dynamic pressure and dipole tilt are primary factors controlling the cusp position with IMF orientation being secondary. As mentioned previously, there are no accurate measurements of solar wind pressure, so an examination into the possible effects of dynamic pressure is not possible, therefore, we may only discuss the implication of dipole tilt and IMF orientation.

Merka et al. (1999) reported that radial field configurations in combination with a "tailward" dipole tilt would result in the cusp location being found at higher latitudes. Indeed, Maynard et al. (2003) have shown that varying IMF $B_{X}$ alters the effective dipole tilt. Also, Opgenoorth et al. (2001) 
reported an unusual cusp encounter by Cluster, where, for moderate changes in the IMF conditions, the cusp position moved from a pre-noon position to a late post-noon position, $\sim 5 \mathrm{~h}$ in MLT. In the current case, the dipole tilt angle is rather small, such that one would expect the cusp to be found at higher latitudes and therefore less flared than when observed for larger, more positive dipole tilt angles. During the time period 05:20-06:15 UT, one can associate the changes observed at Cluster with the changes in IMF $B_{X}$ and $\mathrm{B}_{Z}$, in particular the rough time periods of particular change. During the period of near radial IMF (between $\sim 05: 23$ and 05:40 UT) Cluster observes a transition from a rather unidirectional injected plasma population (after $\sim 05: 25 \mathrm{UT}$ ), to a more isotropic stagnant one (05:30-05:40 UT). Following this period the IMF turns southward for about $12 \mathrm{~min}$ until $\sim 05: 52$ UT, before returning to its more radial state. The corresponding Cluster observations show energy dispersed ion signatures and a return to a more injected particle population (05:40-05:45 UT), consistent with enhanced sub-solar reconnection (we note especially the enhanced flow velocities). However, this is followed by entry into a rather complicated boundary layer, with rather stagnant plasma flow (slightly field-aligned ion pitch angle, not shown) and coexisting high and low energy plasma populations; a low flux magnetosheath-like population co-existing with a more plasma sheet population. Such a population is somewhat similar to the "weakly mixed" PTE signatures discussed by Lundin et al. (2003), describing a population where magnetosheath plasma was newly injected into magnetospheric plasma. This mixing may suggest the region to be a closed LLBL (e.g. Fuselier et al., 2002). Previous studies of similar LLBL properties have suggested that such mixed populations are a result of "double" reconnection (e.g. Le et al., 1996; Onsager et al., 2001), where, under the influence of a northward IMF, lobe reconnection in one hemisphere opens the magnetospheric field lines to the magnetosheath, which are subsequently closed by reconnection in the conjugate hemisphere, trapping the hot magnetospheric and cooler injected magnetosheath plasma. In the current case we find this population during a southward directed IMF, albeit with a comparable $B_{X}$ component. One would expect this configuration to result in reconnection at high latitudes in the Southern Hemisphere. Recent results by Maynard et al. (2003) have shown evidence of high-latitude reconnection during southward IMF, which is moved to higher latitudes with increased IMF, although not poleward of the cusp. In the current case, if we take into consideration the previous highly radial IMF, in conjunction with the possibility of high-latitude/local reconnection (i.e. Savin et al. 2004; Haerendel, 1978), the transition to the current state ( 05:45-05:51 UT) would involve some level of re-configuration. Onsager et al. (2001) have shown there to be a certain pre-processing prior to reconnection and in the current case, this boundary region may be an example of an intermediary stage between dominant reconnection sites, with the radial IMF configuration resulting in a highly unstable and variable reconnection site(s) (e.g. Woch and Lundin, 1992; Maynard et al., 2003).
Subsequent boundaries are consistent with a skimming trajectory of the very edge of the cusp/dayside magnetosphere, with normal rotation predominantly in the $z$ direction. After the final boundary 11 in Fig. 1, we note the rather steady, predominantly radial IMF combining with very turbulent Cluster magnetic field observations to provide little correlation with the clock angles, making identification of a magnetopause rather difficult from a clock angle point of view.

\section{Summary and conclusions}

On 26 February 2001 Cluster encountered the high-altitude cusp region of the Earth's magnetosphere. Over a period from $\sim 04: 00-06: 20$ UT Cluster made 4 separate observations of the cusp, which were identified in data from the PEACE and FGM instruments on board the Cluster spacecraft. By implementing a combination of analysis techniques on these crossings, namely the FGM Discontinuity Analyser (DA) and the PEACE timing analysis (PTA), we were able to determine the orientation and velocity of these boundaries. The results of this analysis have generally shown good agreement with previous studies, where the single spacecraft perspective is upheld with the four spacecraft data. The exception to this conclusion is the orientation of the cusp boundaries 5 and 6 in Fig. 1, which suggests that, for the two consecutive boundary pairs $1-2$ and 5-6, Cluster encounters the cusp from the poleward edge and exits on the equatorward side, rather than observing a simple back and forth motion of the equatorward edge of the cusp. The observation of such "double-cusp" convection may be discussed in terms of a pulsating cusp (Cowley et al., 1991; Lockwood and Smith, 1992), where the two cusp signatures are the result of bursty reconnection resulting in flux tubes convecting over the spacecraft. However, the extent of the cusp signatures, along with the subsequent boundary motions, are more consistent with the motion about the position of the spacecraft of a more permanent external cusp structure. Previous high-altitude cusp studies (Merka et al., 1999 and Eastman et al., 2000) have shown the high-latitude cusp and associated boundary regions to be primarily affected by dipole tilt and solar wind pressure, with IMF dependence secondary. Maynard et al. (2003) have shown that variations in the IMF $B_{X}$ alter the effective dipole tilt angle, which, in turn, effect the position of the cusp. In the present case it appears that the effect of a varying IMF $B_{X}$ has induced latitudinal motion of the cusp region. We have also examined the planar, constant velocity boundary assumption in the derivation of a boundary normal from multi-spacecraft observations, and found that in this case, although planarity was upheld, all crossing had some level of acceleration (as determined by the DA). We have found that for some spacecraft separations in connection with particular instrument resolutions and boundary orientations, the boundary normal may be ill defined.

Acknowledgements. First and foremost, the authors wish to thank the organisers of the recent Cluster workshops, held at ESTEC in the Netherlands, especially H. Laakso and P. Escoubet, that have 
enabled many Cluster teams to begin working together. The authors also wish to thank R. Lundin for helpful discussions. The authors would also like to give special thanks to the instrument teams from Cluster. We also acknowledge C. W. Smith, N. F. Ness and the Bartol Research Institute (BRI), D. J. McComas, R. Skoug and the Los Alamos National Laboratory for use of the level 2 ACE MAG and ACE Solar Wind Experiment data respectively. This work has been supported in the UK by the UCL/MSSL PPARC Rolling grant and in the U.S. by the NASA Sun -Earth Connection program and the Department of Energy.

Topical Editor T. Pulkkinen thanks J. Rae and another referee for their help in evaluating this paper.

\section{References}

Amm, O, Aikip, A., Bosqued, J.-M., Dunlop, M. W., Fazakerley, A., Janhunen, P., Kauristie, K., Lester, M., Sillanpää, I., Taylor, M., Vontrat-Reberac, A., Mursula, K., and André, M.: Mesoscale structure of a morning sector ionospheric shear flow determined by conjugate Cluster II and MIRICALE ground-based observations, Ann. Geophys., 21, 1737, 2003.

Balogh, A., Dunlop, M. W., Cowley, S. W. H., Southwood, D. J., Thomlinson, J. G., Glassmeier, K.-H., Musmann, G., Lühr, H., Buchert, S. H., Acuña, M., Fairfield, D. H., Slavin, J. A., Riedler, W., Schwingenschuh, K., Kivelson, M. G., and the Cluster magnetometer team: The Cluster Magnetic field Investigation, Space Science Reviews, 79, 65-92, 1997.

Balogh, A., Carr, C. M., Acuña, M. H., Dunlop, M. W., Beek, T. J., Brown, P., Fornacon, K.-H., Georgescu, E., Glassmeier, K.-H., Harris, J., Musmann, G., Oddy, T, and Schwingenschuh, K.: The Cluster Magnetic Field Instrument: overview of in-flight performance and initial results, Ann. Geophys., 19, 1207-1217, 2001.

Boardsen, S. A., Eastman, T. E., Sotirelis, T., and Green, J. L.: An Emperical Model of the High-Latitude Magnetopause, J. Geophys. Res., 105, 23 193-23 219, 2000.

Bosqued, J.-M., Phan, T. D., Dandouras, I., Escoubet, C. P., Rème, H., Balogh, A., Dunlop, M. W., Alcaydé, D., Amata, E., Bavassano-Cattaneo, M.-B., Bruno, R., Carlson, C., DiLellis, A. M., Eliasson, L., Formisano, V., Kistler, L. M., Klecker, B., Korth, A., Kucharek, H., Lundin, R., McCarthy, M., McFadden, J. P., Möbius, E., Parks, G. K., and Sauvaud, J.-A.: Cluster observations of the high-latitude magnetopause and cusp: initial results from the CIS ion instruments, Ann. Geophys., 19, 1545-1566, 2001.

Cargill, P. J.: A model for plasma flows and shocks in the highaltitude cusp, J. Geophys. Res., 104, 14 647-14 653, 1999.

Cargill, P. J., Dunlop, M. W., Balogh, A., and the FGM team: First Cluster results of the magnetic field structure of the mid- and high-altitude cusps, Ann. Geophys., 19, 1533-1543, 2001.

Cowley, S. W. H. and Lewis, Z. V.: Magnetic trapping of energetic particles on open dayside boundary layer flux tubes, Planet. Space Sci., 38, 1343-1350, 1990.

Cowley, S. W. H., Freeman, M. P., Lockwood, M., and Smith, M. F.: The ionospheric signature of Flux transfer events, in Clusterdayside polar cusp, ESA SP-330, edit. C. I. Barron, European Space Agency Publications, Nordvijk, The Nederlands, 105112,1991

Chapman, S. and Ferraro, V. C. A: A new theory of magnetic storms, Part 1. The initial phase, Terr. Mag. Atmos. Elect., 36, 77, 1931.
Chen, S.-H., Boardsen, S. A., Fung, S. F., Green, R. L., Kessel, R. L., Tan, L. C., Eastman, T. E., and Craven, J. D.: Exterior and interior polar cusps: Obervations From Hawkeye, J. Geophys. Res., 102, 11335-11 347, 1997.

Crooker, N. U.: Reverse Convection, J. Geophys. Res., 97, 1936319372, 1992.

Décréau, P. M. E, Fergeau, D., Krasnoselskikh, V., Lévêque, M., Martin, Ph., Randriamboarison, O., Sené, F. X., Trotignon, J. G., Canu, P., Mögensen, P. B., and WHIPSER investigators: WHIPSER, A Resonance Sounder and Wave Analyser: Performance and Perspectives for the Cluster Mission, Space Science Reviews, 79, 157-193, 1997.

Décréau, P. M. E, Fergeau, P., Krasnoselskikh, V., Le Guirriec, E., Lévêque, M., Martin, Ph., Randriamboarison, O., Rauch, J. L., Sené, F. X., Séran, H. C., Trotignon, J. G., Canu, P., Cornilleau, N., de Féraudy, M., Alleyne, H., Yearby, H., Mögensen, K., Gustafsson, P. B., André, G., Gurnett, D. C., Darrouzet, F., Lemaire, J., Harvey, C. C., Travnicek P., and WHIPSER experimenters: Early results from the Whisper instrument on Cluster: an overview, Ann. Geophys., 19, 1241-1258, 2001.

Dubinin, E., Skalsky, A., Song, P., Savin, S., Kozyra, J., Moore, T. E., Russell, C. T., Chandler, M. O., Federov, A., Avanov, L., Sauvaud, J. A., and Friedel, R. H. W.: Polar-Interball coordinated observations of plasma and magnetic field characteristics in the regions of the northern and southern distant cusps, J. Geophys. Res., 107, 1053, 2002.

Dungey, J. W.: Interplanetary magnetic field and the auroral zones, Phys. Rev. Lett., 6, 47-48, 1961.

Dunlop, M. W., Cargill, P., Stubbs, T., and Woolliams, P.: The high altitude Cusps: HEOS-2, J. Geophys. Res., 105, 27 509-27 517, 2000.

Dunlop, M. W. and Woodward, T. I.: Multi-spacecraft Discontinuity Analysis: Orientation and Motion, in Analysis Methods for Multi-Spacecraft Data, edited by G. Paschmann and P. Daly, ISSI, ESA publications division, 2000.

Dunlop, M. W., Balogh, A., Glassmeier, K.-H., and FGM team: Four-point Cluster application of magnetic field analysis tools: The discontinuity analyser, J. Geophys. Res., 10, 1029/2001JA005089, 2002.

Eastman, T. E., Boardsen, S. A., Chen, S.-H., and Fung, S. F.: Configuration of high-latitude and high-altitude boundary layers, J. Geophys. Res., 105, 23 221-23 238, 2000.

Farrell, W. M. and Van Allen, J. A.: Observations of the Earth's polar cleft at large radial distances with the Hawkeye 1 satellite, J. Geophys. Res., 95, 20 945, 1990.

Federov, A., Dubinin, E., Song, P., Budnick, E., Larson, P., and Sauvaud, J.-A.: Plasma characteristics of High-Altitude cusp for steady southward-dawnward IMF, Adv. Space. Res., 1435-1444, 2000.

Frank, L. A.: Plasma in the Earth's Polar Magnetosphere, J. Geophys. Res., 22, 5202-5219, 1971.

Fritz, T. Q., Zong, J., Chen, J., and Coombs, P.: Daly and the CAMMICE and RAPID teams, Simultaneous measurements of Polar and Cluster in the dayside cusp, EGS XXVII General Assembly, Nice, France, Abstract EGS02-A-05111, 2002.

Fung, S. F., Eastman, T. E., Boardsen, S. A., and Chen, S.-H.: Highaltitude cusp positions sampled by the Hawkeye satellite, Phys. Chem. Earth, 22, 7-8, 1997.

Fuselier, S. A., Berchem, J., Trattner, K. J., and Friedel, R.: Tracing ions in the cusp and low-latitude boundary layer using multispacecraft observations and a global MHD simulation, J. Geophys. Res., 107, 1226-1234, 2002. 
Harvey, C. H.: Spatial gradients and the Volumetric Tensor, in Analysis Methods for Multi-Spacecraft Data, edited by G. Paschmann and P. Daly, ISSI, ESA publications division, 2000.

Haerendel, G., Paschmann, G., Sckopke, N., and Rosenbauer, H.: The Frontside Boundary layer of the Magnetopause and the Problem of Reconnection, J. Geophys. Res., 83, 3195-3216, 1978.

Hedgecock, P. C. and Thomas, B. T.: HEOS Observations of the Configuration of the Magnetosphere, J. Geophys. Res., 41, 391403, 1975.

Heikkila, W. J. and Winningham, J. D.: Penetration of Magnetosheath Plasma to Low altitudes through the Dayside Magnetospheric cusps, J. Geophys. Res., 76, 4, 1971.

Hultqvist,B., Oieroset, M., Pashmann, G., Truemann, R.: Plasma transfer processes at the magnetopause, Space Science Reviews, 88, 207-283, 1999.

Johnstone, A. D., Alsop, C., Burge, S., Carter, P. J., Coates, A. J., Coker, A. J., Fazakerley, A. N., Grande, M., Gowen, R. A., Gurgiolo, C., Handcock, B. K., Narheim, B., Preece, A., Sheather, P. H., Winningham, J. D., Woddliffe, R. D.: PEACE: a Plasma electron and current experiment, Space Science Reviews, 79, 351398, 1997.

Kessel, R. L., Chen, S-H., Green, J. L., Fung, S. F., Boardsen, S. A., Tan, L. C., Eastman, T. E., Craven, J. D., and Frank, L. A.: Evidence of high-altitude reconnection during northward IMF : Hawkeye observations, 23, 583-586, 1996.

Krauklis, I, Fazakerley, A., Owen, C. J., Carter, P., Dunlop, M., Coates, A. J., Szita, S., Taylor, M. G. G. T., Travnicek, P., Watson, G., Wilson, R. J.: Preliminary two point observations of the mid-altitude cusp by Cluster PEACE and FGM, Ann. Geophys., 19, 1579-1588, 2001.

Lavraud, B., Dunlop, M. W., Phan, T. D., Rème, H., Bosqued, J.-M., Dandouras, I., Sauvaud, J.-A., Lundin, R.,. Taylor, M. G. G. T, Cargill, P., Mazelle, C., Escoubet, C. P., Carlson, C., McFadden, J. P., Parks, G. K., Moebius, E., Kistler, L., Bavassano-Cattaneo, M.-B., Korth, A., Klecker, B., and Balogh, A.: Cluster Observations of the Exterior Cusp and its Surrounding Boundaries under Northward IMF, J. Geophys. Res., 29, 1995, 2002.

Le, G., Russell, C. T., Gosling, J. T., and Thomsen, M. F.: ISEE observations of low-latitude boundary layer for northward interplanetary magnetic field: Implications for cusp reconnection, J. Geophys. Res., 101, 27 239-27 249, 1996.

Lockwood, M. and Smith, M. F.: The Variation of Reconnection Rate at the dayside magnetopause and Cusp Ion precipitation, J. Geophys. Res., 97, 14 841-14 847, 1992.

Lockwood, M., Opgenoorth, H., van Eyken, A. P., Fazakerley, A., Bosqued, J.-M., Denig, W., Wild, J., Cully, C., Greenwald, R., Lu, G., Amm, O., Frey, H., Strømme, A., Prikryl, P., Hapgood, M. A., Wild, M. N., Stamper, R., Taylor, M., McCrea, I., Kauristie, K., Pulkkinen, T., Pitout, F., Balogh, A., Dunlop, M., Rème, H., Behlke, R., Hansen, T., Provan, G., Eglitis, P., Morley, S. K., Alcayde, D., Blelly, P.-L., Moen, J., Donovan, E., Engebretson, M., Lester, M., Waterman, J., Marcucci, M. F.: Coordinated Cluster, ground-based instrumentation and low-altitude satellite observations of transient poleward-moving events in the ionosphere and in the tail lobe, Ann. Geophys., 19, 1613-1640, 2001.

Lockwood, M., Fazakerley, A., Opgenoorth, H., Moen, J., van Eyken, A. P., Bosqued, J.-M., Lu, G., Eglitis, P., McCrea, I. W., Cully, C., Hapgood, M. A., Wild, M. N., Stamper, R., Taylor, M., Wild, J., Provan, G., Amm, O., Kauristie, K., Pulkkinen, T., Strømme, A., Prikryl, P., Pitout, F., Dunlop, M., Balogh, A., Rème, H., Behlke, R., Denig, W., Hansen, T., Greenwald, R.,
Morley, S. K., Alcayde, D., Blelly, P.-L., Donovan, E., Engebretson, M., Lester, M., Waterman, J., Marcucci, M. F.: Coordinated Cluster and ground-based instrument observations of transient changes in the magnetopause boundary layer during northward IMF, Ann. Geophys., 19, 1641-1654, 2001.

Lundin, R.: Plasma Composition and flow characteristics in the magnetospheric boundary layers connected to the polar cusp, in The Polar Cusp, edited by J. A. Holtet A. Egeland, and D. Reidel Publishing Company, 1985.

Lundin, R., Sauvaud, J.-A., Rème, H., Balogh, A., Dandouras, I., Bosqeud, E., Carlson, J. M., Parks, C., Möbius, G. K., Kistler, E., Klecker, L. M., Amata, B., Formisano, V., Dunlop, M., Eliasson, L., Korth, A., Lavraud, B., and McCarthy, M.: Evidence for impulsive solar wind plasma penetration through the dayside magnetopause, Ann. Geophys., 21, 457-472, 2003.

Maynard, N. C., Ober, D. M., Burke, W. J., Scudder, J. D., Lester, M., Dunlop, M., Wild, J. A., Grocott, A., Farrugia, C. J., Lund, E. J., Russell, C. T., Weimer, D. R., Siebert, K. D., Balogh, A., Andre, M., and Rème, H.: Polar, Cluster and SuperDARN evidence for high-latitude merging during southward IMF: Temporal/spatial evolution, Ann. Geophys., 21, 2233-2258, 2003.

Merka, J., Safrankova, J., and Òemeèek, Z.: Interball observations of the High-Altitude cusp-like plasma: a statistical study, Czech. J. Phys., 49, 695-709, 1999.

Merka, J., Safrankova, J., and Nemecek, Z. et al.: High-altitude cusp: INTERBALL observations, Adv. Space Res., 25, 14251434, 2000.

Newell, P. T. and Meng, C.-I.: Mapping the dayside ionosphere to the magnetosphere according to particle precipitation characteristics, Geophys. Res. Lett., 19, 6, 609-612, 1992.

Onsager, T. G., Scudder, J. D., Lockwood, M., and Russell, C. T.: Reconnection at the high-latitude magnetopause during northward interplanetary magnetic field conditions, J. Geophys. Res., 11, 25 467-25 488, 2001.

Opgenoorth, H. J., Lockwood, M., Alcayde, D., Donovan, E., Engebretson, M. J., van Eyken, A. P., Kauristie, K., Lester, M., Moen, J., Waterman, J., Alleyne, H., Andre, M., Dunlop, M. W., Cornilleau-Wehrlin, N., Decreau, P. M. E., Fazerkerley, A., Reme, H., Andre, R., Amm, O., Balogh, A., Behlke, R., Blelly, P. L., Boholm, H., Borälv, E., Bosqued, J. M., Buchert, S., Candidi, M., Cerisier, J. C., Cully, Ch., Denig, W. F., Doe, R.,Eglitis, P., Greenwald, R. A., Jackal, B., Kelly, J. D., Krauklis, I., Lu, G., Mann, I. R., Marcucci, M. F., McCrea, I. W., Maksimovic, M., Massetti, S., Masson, A., Milling, D. K., Orsini, S., Pitout, F., Provan, G., Ruohoniemi, J. M.,Samson, J. C., Schott, J. J., Sedgemore-Schulthess, F., Stamper, R., Stauning, P., Strömme, A., Taylor, M., Vaivads, A., Villain, J. P., Voronkov, I., Wild, J., and Wild, M.: Coordinated Ground-Based, Low Altitude Satellite and Cluster Observations on Global and Local Scales During a Transient Postnoon Sector Excursion of the Magnetospheric Cusp, Ann. Geophys., 19, 1367-1398, 2001.

Owen, C. J., Fazakerley, A. N., Carter, P. J., Coates, A. J., Krauklis, I. C., Szita, S., Taylor, M. G. G. T., Trávníěek, P., Watson, G., Wilson, R. J., Balogh, A., and Dunlop, M. W.: Cluster PEACE Observations of Electrons During Magnetospheric Flux Transfer Events, Ann. Geophys., 19, 1509-1522, 2001.

Paschmann, G., Haerendel, G., Sckopke, N., Rosenbauer, H., and Hedgecock, P. C.: Plasma and magnetic field characteristics of the distant polar cusp near local noon the entry layer, J. Geophys. Res., 81, 2883, 1976.

Pederson, A, Cornilleau-Wehrlin, N., De La Porte, B., Roux, A., Bouabdellah, A., Décréau, P. M. E., Lefeuve, F., Sène, F. X., 
Gurnett, D., Huff, R., Gustafsson, G., Holmgren, G., Wooliscroft, L., Alleyne, H. S. C, Thomson, J. A., and Davies, P. H. N.: The Wave Experiment Consortium (WEC), Space Science Reviews, 79, 93-106, 1997.

Press, W. H., Teukolsky, S. A., Vettering, W. T., and Flannery, B. P.: Numerical Recipes in C, 2nd edition, Cambridge University Press, 1999.

Rae, I. J., Lester, M., Milan, S. E., Fritz, T. A., Grande, M., and Scudder, J. D.: Polar observations of the time varying cusp, J. Geophys. Res., 106, 19 057-19 065, 2001.

Rème, H., Aoustin, C., Bosqued, J. M., Dandouras, I., Lavraud, B., Savaud, J. A., Barthe, A., Bouyssou, J., Camus, T., Coeur-Joly, O., Cros, A., Cuvilo, J., Ducay, F., Garbarowitz, Y., Medale, J. L., Penou, E., Perrier, H., Romefort, D., Rouzaud, J., Vallat, C., Alcaydé, D., Jacquey, C., Mazelle, C., d’Uston, C., Möbius, E., Kistler, L. M., Crocker, K., Granoff, M., Mouikis, C., Popecki, M., Vosbury, M., Klecker, B., Hovestadt, D., Kucharek, H., Kuenneth, E., Paschmann, G., Scholer, M., Sckopke, N., Seidenschwang, E., Carlson, C. W., Curtis, D. W., Ingraham, C., Lin, R. P., McFadden, J. P., Parks, G. K., Phan, T., Formisano, V., Amata, E., Bavassano-Cattaneo, M. B., Baldetti, P., Bruno, R., Chionchio, G., Di Lellis, A., Marcucci, M. F., Pallocchia, G., Korth, A., Daly, P. W., Graeve, B., Rosenbauer, H., Vasyliunas, V., McCarthy, M., Wilber, M., Eliasson, L., Lundin, R., Olsen, S., Shelley, E. G., Fuselier, S., Ghielmetti, A. G., Lennartsson, W., Escoubet, C. P., Balsiger, H., Friedel, R., Cao, J-B., Kovrazhkin, R. A., Papamastorakis, I., Pellat, R, Scudder, J., and Sonnerup, B.: First multispacecraft ion measurements in and near the Earth's magnetosphere with the identical Cluster ion spectrometry (CIS) experiment, Ann. Geophys., 19, 1303-1354, 2001.

Russell, C. T., Melliot, M. M., Smith, E. J., and King, J. H.: Multiple Spacecraft Observations of Interplanetary Shocks: Four Spacecraft Determinations of Shock Normals, J. Geophys. Res., 88, 4739-4748, 1983.

Russell, C. T.: Polar Eyes the Cusp, Proc. Cluster-II workshop on multiscale / multipoint plasma measurements, London, 22-24 September 1999, ESA SP-449, 47, 2000.

Sandahl, I., Lundin, R., Yamauchi, M., Eklund, U., Safrankova, J., Nemecek, Z., Kudela, K., Lepping, R. P., Lin, R. P., Lutsenko V. N., and Sauvaud, J.-A.: Cusp and Boundary layer observations by INTERBALL, Adv. Space Res., 20, 823-832, 1997.

Savin, S. P., Borodkova, N. L., Budnik, E., Federov, A. O., Klimov, S. I., et al.: Interball tail probe measurements in outer cusp boundary layers, in: Geospace Mass and Energy Flow: Results from the International Solar-Terrestrial Physics Program, edited by Horwitz, J. L., Gallagher, D. L., and Peterson, W. K., Geophyscial Monograph 104, Am. Geophys. Union, Washington D.C., 25-44, 1998.

Savin, S., Zelenyi, L., Romanov, S., Sandahl, I., Pickett, J., Amata, E., Avanov, L., Blecki, J., Budnik, E., Büchner, J., Cattell, C., Consolini, G., Fedder, J., Fuselier, S., Kawano, H., Klimov, S., Korepanov, V., Laoutte, D., Marcucci, F., Mogilevsky, M., Nemecek, Z., Nikutowski, B., Nozdrachev, M., Parrot, M., Rauch,J. L., Romanov, V., Romantsova, T., Russell, C. T., Safrankova, J., Savaud, J. A., Skalsky, A., Smirnov, V., Staiewicz, K., Trotignon, J. G, and Yu. Yermolaev, Magnetosheath-cusp interface, Ann. Geophys., 22, 183-212, 2004.

Smith, M. F. and Lockwood, M.: Earth's Magnetospheric Cusps, Rev. Geophys., 34, 232, 1996.

Smith, C. W., Acuna, M. H., Burlaga, L. F., L’Heureux, J., Ness, N. F., and Scheifele, J.: First Results from the ACE Magnetic Fields Experiment, Space Science Reviews, 86, 613-632, 1998.
Spreiter, J. R., Alksne, A. Y., and Summers, A. L.: External aerodynamics of the magnetosphere, in Physics of the magnetosphere, edited by R. L. Carovillano, McClay, J. F., and Radoski, H. R., 301-375, Reidel, D., Hingham, Mass., 1968.

Szita, S., Fazakerley, A. N., Carter, P. J., James, A. J., Trávníěek, P., Watson, G., Andre, M., Eriksson, A., and Torkar, K.: Cluster PEACE observations of electrons of spacecraft origin, Ann. Geophys., 19, 1721-1730, 2001.

Taylor, M. G. G. T., Fazakerley, A., Krauklis, I. C., Owen, C. J., Trávníek, P., Dunlop, M., Carter, P., Coates, A. J., Szita, S., Watson, G., and Wilson. R. J.: Four point measurements of electrons using PEACE in the high-altitude cusp, Ann. Geophys., 19, 1567-1578, 2001.

Taylor, M. G. G. T. and Cargill, P. J.: A Magnetohydrodynamic model of plasma flow in the high-altitude cusp, J. Geophys. Res., 107, 10.1029/2001JA900159, 2002.

Trattner, K. J., Fuselier, S. A., Yeoman, T. K., Korth, A., Fraenz, M., Mouikis, C., Kucharek, H., Kistler, L. M., Escoubet, C. P., Rème, H., Dandouras, I., Sauvaud, J. A., Bousqued, J. M., Klecker, B., Carlson, C., Phan, T., McFadden, J. P., Amata, E., and Eliasoon, L.: Cusp Structures: Combining multi-spacecraft observations with ground-based observations, Ann. Geophys., 21, 2031-2041, 2003.

Torkar, K., Riedler, W., Escoubet, C. P., Fehringer, M., Schmidt, R., Grard, R. J. L., Arends, H., Rüdenauer, F., Steiger, W., Narheim, B. T., Svenes, K., Torbert, R., Andre, M., Fazakerley, A., Goldstein, R., Olsen, R. C., Pedersen, A., Whipple, E., and Zhao, H.: Active Spacecraft control for Cluster-implementation and first results, Ann. Geophys., 19, 1289-1302, 2001.

Weimer, D. R., Ober, D. M., Maynard, N. C., Burke, W. J., Collier, M. R., McComas, D. J., Ness, N. F., and Smith, C. W.: Variable time delays in the propagation of the interplanetary magnetic field, J. Geophys. Res., 107, No. A8, 1210, 10.1029/2001JA009102, 2002.

Wilken, B., Axford, W. I., Daglis, I., Daly, P., Güttler, W., Ip, W. H., Korth, A., Kremser, G., Livi, S., Vasyliunas, V. M., Woch, J., Baker, D., Belian, R. D., Blake, J. B., Fennell, J. F., Lyons, L. R., Borg, H., Fritz, T. A., Gliem, F., Rathje, R., Grande, M. Hall, D., Kecsuméty, K., Mckenna-Lawlor, s., Mursula, K., Tanskanen, P., Pu, Z., Sandahl, I., Sarris, E. T., Scholer, M., Schulz, M., Søraas, F., and Ullaland, S.: RAPID-The imaging energetic particle spectrometer on Cluster, Space Sci. Rev., 79, 399-473, 1997.

Wilken, B., Daly, P. W., Mall, U., Aarsnes, K., Baker, D. N., Belian, R. D., Blake, J. B., Borg, H., Buchner, J., Carter, M., Fennell, J. F., Friedel, R., Fritz, T. A., Gliem, F., Grande, M., Kecskemety, K., Kettmann, G., Korth, A., Livi, S., McKenna-Lawlor, S., Mursula, K., Nikutowski, B., Perry, C. H., Pu, Z. Y., Roeder, J., Reeves, G. D., Sarris, E. T., Sandahl, I., Søraas, F., Woch, J., and Zong, Q. G.: First results from the RAPID imaging energetic particle spectrometer on board Cluster, Ann. Geophys., 19, 1355-1366, 2001.

Woch, J. and Lundin, R.: Magnetosheath plasma precipitation in the polar cusp and its control by the interplanetary magnetic field, J. Geophys. Res., 97, 1421-1430, 1992.

Zelenyi, L. M., Trska, P., and Petrukovich, A. A.: INTERBALLdual probe and dual mission, Adv. Space Res., 20, 549-557, 1997.

Zhou, X.-W. and Russell, C. T.: The Location of the high-latitude polar cusp and the shape of the surrounding magnetopause, J. Geophys. Res., 102, 105-110, 1997. 